\title{
Slawomir Brzoska, [A Year of a Wandering Life], 2 vols., Uniwersytet Artystyczny, Poznań 2017-2019
}

\author{
Beata Frydryczak \\ (Institute of European Culture, Adam Mickiewicz University) \\ ORCID 0000-0003-1700-1918
}

The two-volume, richly illustrated monograph by Sławomir Brzoska is a report from a journey around the world that the artist made in 2007-2008. At the same time, the two-volume work is a form of presentation of the artistic endeavor. "Sketches on a Journey" undertaken during the trip, which fits on the borderline of art and life. The artist describes his journey along the highways and byways of South America, Australia, Asia, the Middle East, through cities, secluded spots, and landscapes, although it should be put differently: through people, cultures, experiences, events, and impressions in a situation full of openness to what awaits us on the way, as if we-the readers-were witnessing a performance, with the book becoming its frame. It is difficult to refer to the monograph itself, leaving aside the artistic endeavors which were one of the dimensions of this journey and which contribute important photographic material to both volumes.

Taking into account the description of the course of the journey, the monograph can be classified in a literary genre between reportage and travelogue. In fact, it can be assumed that this is the interpretation which comes to mind first. And this is how it can be read, since it describes all the hardships of the year-long journey undertaken by the author. But that belief would be misleading. It is impossible to think of this monograph as just a report of a trip, even the most spontaneous one which surrenders to the importance of the moment and place. The uniqueness of this narrative lies in the fact that, by combining the many possibilities of its interpretation, it actually shows how the journey takes on the characteristics of what is performative and becomes a wandering: between places, people, experiences, reflections, and observations, transforming itself into what Henryk Bereza aptly calls a form of "life-writing": rich in meanings, sometimes deeply moving, never 
indifferent or objective, because it results from experience rather than observation.

A Year of a Wandering Life is a chronicle of a journey that becomes a wandering, existential metaphor-sometimes metaphysical, leading through light and darkness. This is yet another facet of this book, which takes on expression along with the way the author has travelled. Therefore, it turns out that its content is in fact a road, and the journey becomes an experience, at times of an extreme nature, which is born in motion, with every step, every breath, every place visited, and every person encountered. In the journey undertaken by Brzoska, each chosen path may turn out to be a fate, a place to rest - a threat, and the road itself may lead nowhere: it is determined randomly, day by day, from section to section, without imagining how long one will stay in a given place and what might await the wanderer in the next place. In this sense, the journey described and travelled evokes one of the oldest and most universal metaphors of human life, brought into the canon of a wandering life by Ulysses, who wanted to return home, and by the Wandering Jew, who was looking for a place to live. It was perfectly put by Brzoska: "Throughout these few months of permanent movement, the road 'sunk' into me and I became a part of it" (vol. 2, 45). It wasn't the journey that was the road, it was the traveler who became the road.

Georg Simmel said that a wanderer is someone for whom the road is home: individual places are only stops and the destination remains undefined. This is someone who has not given up the freedom to come and go ("today he comes and tomorrow he stays"). Simmel's wanderer remains uprooted and has no connection to a specific place in space; he sets off on his way, usually alone, and anonymously arrives in a new place. If we treat this short description as a definition, then $A$ Year of a Wandering Life complements it perfectly and represents it: "The essence of this journey was lonely moments, unlimited being vis-a-vis the world, and the more the space around me was wild, lifeless, deserted, rocky, archaic, the more excited I felt" (vol. 2, 217). It is a metaphysical dimension of a journey that takes place not so much in space as in experiencing it through direct and immediate perception, sometimes the experience is of a borderline nature.

This experience is manifested in the signs of presence that the author-artist-wanderer left along his path, which will never return: stones entwined with colored yarn as open signs of his presence and the effect of spontaneous artistic action. With this artistic gesture, the artist entered the landscape, added something of himself to it, and at the same time transformed it, leaving it forever changed. In this action, the colored stone lost its properties and became a minimal work of art from the borderlands of Land Art: the "yarn-stone" became more real than the rock-and through the contrasting color, more material than the desert or rubble.

For Brzoska, wandering is the key to what is existential (life, sometimes on the edge), artistic (art, expressed in spontaneous actions), and topographical (landscape 
traversed and contemplated, and at the same time almost touched). These three dimensions interweave with each other, overlap each other so that they become one, as if they deliberately did not allow themselves to be separated, or merge with each other so that it is impossible to see the moment of transition between themjust as it is impossible to determine when a contemplated landscape takes on a tangible character and becomes one in which the wanderer participates according to the rights of all-human and non-human-subjects inhabiting it. Then not only are the eyes full of sights, but all the other senses begin to take part in it: every step, movement of muscles, and gulp of air reflects the essence of the landscape being traversed. The desert landscape takes on a metaphysical nature, opening up unlimited space to itself, but when it invades the eyes and mouth in the form of a sandstorm, it touches the wanderer with every grain of sand; it becomes a tactile impression, according to the principle that "touching means being touched": it wasn't he who touched the desert, it was the desert that touched him, it embraced him with its arms so much so that he was left breathless. In such a dimension, life becomes an extremely perceptible value, tasting better and better with every event, with every situation, artistic one as well, which becomes its, life's, expression. This fragment is significant:

I was fully aware that my feet belonged to the land on which I was standing, and as there was no division between the parts of my body, my guts and hands and head also belonged to this place. The place has no borders. The ground under my feet, which occupies several tens of centimeters, is not separated from what's next. And so to the horizon and beyond. Thanks to this, even those areas that I have not seen are also part of me and I am part of them. This growing awareness of community and mutual belonging fostered a sense of happiness and I could not wait for the morning to return to the desert again. (vol. 2, 217)

The element that unites it is the topographical experience, which can be born only on the road, not just in the form of recognition of the terrain and its characteristic points, but also of the materiality of the road under our feet, of all the external stimuli that make the impressions take on an exceptional intensity; it is the experience shaped on the road, focused on the details, recognizing the places. The road means abandoning the observation point in order to enter space, to reach a place, to be in the landscape. This essentially practical aspect of being in the landscape is based on the experience of wandering and the difficulty of settling down or undertaking actions designed to create one's own safe space. Wandering in this aspect is akin to creating space which becomes a space of sensory experience-the more intense the more the place remains a mystery. But it is also a performative experience in which art and life, road and senses, become one.

The key to reading Brzoska's journey, described in both volumes of the monograph, is the topographic experience inscribed in the encounter with the landscape. 
It really determines the rhythm of the trip and the intensity of the feelings that are amplified with each step taken, and sometimes with staying put. For some time-not metric or clockwork but metaphysical, counted by the number of steps, the length of a conversation, or listening to oneself and one's surroundings - this kind of "encounter with the landscape" requires a form of perception other than a purely visual one, which means that the wanderer has to open himself up to poly-sensory experience, the constant presence of senses, in order for perception to take on an active character and the form of "being in the landscape." It is a situation where we cannot keep our distance, where we are surrounded by nature and its shaping factors, and it is not indifferent to us. Being in the landscape is a bodily experience that involves all the senses, through smells, sounds, movement, and haptic sensations: when the wind blows through your hair, rain drops fall on your face, your legs get stuck in the mud, or you are soothed by the singing of birds. It is the active presence of the human body in the evaluative experience. Here, as Arnold Berleant says, events are turned into experiences. These in turn create the world that we inhabit. As a wanderer, a human being becomes part of the landscape, and so he is situated in the landscape. Wandering allows one to transform an image into smell, sound, and tactile quality. The senses, understood as an integrated sensorium, are primarily active. In topographical experience, we do not abandon perception, but, as Ingold claims, we intensify consciousness. The two volumes of A Year of a Wandering Life testify with all openness to this kind of experience.

It is difficult to overestimate the value of this two-volume monograph. It is a type of narrative that comes from deep within. It is extremely personal, sincere, sometimes revealing, but at all times aiming at the truth of the moment and of the impressions. What is more, it is a narrative which attests to excellent writing skills, a knack for the written word, and the ability to weigh every expression. The story is a real page-turner, with the reader waiting for more meetings with people, descriptions of landscapes and places visited, and events and fortuitous incidents. Certainly, it becomes an experience for the reader, and thus opens up another layer of its potential. 